\title{
The incidence of radiologically demonstrable aneurysm and arteriovenous malformation in spontaneous subarachnoid haemorrhage
}

\author{
C. R. BARRAClOUgh \\ M.R.C.P.
}

The Midland Centre for Neurosurgery and Neurology, Smethwick, Warley, West Midlands

\begin{abstract}
Summary
The incidence of radiologically demonstrable aneurysm and arteriovenous malformation (AVM) in patients admitted to the Midland Centre for Neurosurgery and Neurology (MCNN) with the diagnosis of spontaneous subarachnoid haemorrhage (SAH) between 1959-80 inclusive was determined. Bilateral carotid angiography (BCA) showed $65.8 \%$ to have one or more aneurysms and $7.5 \%$ an AVM, each figure including $0.6 \%$ with both conditions. When BCA was negative, $65.8 \%$ proceeded to vertebral angiography (VA) and of these $12.5 \%$ were shown to have an aneurysm and $4.2 \%$ an AVM.

The probability of demonstrating an aneurysm by either of these radiological methods is an important factor in deciding whether or not to proceed to angiography, especially in patients presenting an above average anaesthetic or operative risk, bearing in mind the high mortality of untreated aneurysm in this condition and the improved prognosis when successful surgical management is possible.
\end{abstract}

\section{Introduction}

The most common cause of spontaneous subarachnoid haemorrhage (SAH) is rupture of a saccular aneurysm on the circle of Willis or its branches or vessels of supply. Cerebral angiography remains the most reliable pre-operative way of demonstrating the presence and site of such an aneurysm, although this can frequently be suspected on clinical grounds and occasionally demonstrated by computerized axial tomography. However, angiography does not always reveal an aneurysm even though one may subsequently be shown to be present either at operation, post-mortem or repeat angiography at a later date. Perhaps the commonest explanation is that some aneurysms may be completely filled with recent thrombus and therefore fail to fill with radioopaque contrast (Dandy, 1944; Richardson, 1969). It also seems likely that some aneurysms and arteriovenous malformation (AVM) may be so minute that they destroy themselves in the process of rupture (Hassler, 1961). Whatever the reason, the long-term prognosis in patients who fail to have a demonstrable aneurysm or AVM is favourable 3 . compared to those in whom such a lesion is shown in $_{0}$ (Hook, 1958; Hayward, 1977). It is therefore ${ }^{\circ}$ important to know the incidence of radiologically $\sigma$ demonstrable aneurysm or AVM in patients with $\underset{\perp}{\not}$ spontaneous SAH as a guide to the advisability and 0

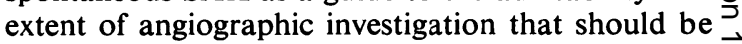
performed. This is particularly relevant for those $\vec{T}$ patients in whom age, neurological deficit or the $\frac{\mathbb{O}}{0}$ presence of other vascular pathology such as known hypertension or ischaemic heart disease mitigates against the decision to perform what is otherwige $\overrightarrow{0}$ an essential investigation.

A large series of patients admitted to a specialiof neurosurgical centre with the diagnosis of spon aneous SAH was reviewed not only to determine the incidence of radiologically demonstrable aneurysm $\overline{0}$ or AVM but also to see whether or not general improvement in anaesthetic and radiological tech- $\mathcal{Q}$ niques in recent years had resulted in a higher in- $\overrightarrow{\vec{O}}$ cidence of aneurysm detection.

\section{Patients and methods}

The results of angiographic investigation of patients admitted to the Midland Centre for Neuro- 3 . surgery and Neurology (MCNN) during the 22-year period 1959-80 with the diagnosis of acute spon- $\frac{3}{2}$. taneous SAH were reviewed. The diagnosis of acute 0 spontaneous SAH was made either by the combination of a typical history with the finding of $ᄋ$ uniformly blood-stained cerebrospinal fluid at lum- $\supset$ bar puncture or, in recent years, by the combination of a typical history with demonstration of blood in the intracranial cisterns on computerized axial $\odot$ tomography in patients in whom lumbar puncture $N$ was not performed because of suspected haematoma causing prohibitive rise of intracranial pressure.

Subarachnoid haemorrhage secondary to hea $\mathrm{d}_{0}^{2}$ injury, intracranial tumour or known haemorrhagic $\frac{\mathbb{\Phi}}{\Phi}$ diathesis is not included, and only patients surviving $\stackrel{?}{?}$ to angiography and those in whom the initial 0 angiographic investigation was carotid angiography $\overrightarrow{0}$ 
performed at the MCNN are considered. Of the total remaining patients with spontaneous SAH, a small number $(<1 \%)$ had only unilateral carotid angiography and these are also excluded from review.

\section{Results}

A total of 2146 patients with spontaneous SAH were submitted to bilateral carotid angiography (BCA) during the 22-year period, and the results are

TABLE 1. Results of bilateral carotid angiography in spontaneous subarachnoid haemorrhage (1959-80 inclusive)

\begin{tabular}{cccc}
\hline $\begin{array}{c}\text { Total number } \\
\text { of patients }\end{array}$ & $\begin{array}{c}\text { Aneurysm(s) } \\
\text { alone }\end{array}$ & $\begin{array}{c}\text { Arteriovenous Aneurysm }+ \\
\text { malformation } \\
\text { alone }\end{array}$ & $\begin{array}{c}\text { arteriovenous } \\
\text { malformation }\end{array}$ \\
\hline 2146 & 1399 & 148 & 14 \\
$\%$ & 65.2 & 6.9 & 0.6 \\
\hline
\end{tabular}

shown in Table 1. Aneurysm, AVM or both were demonstrated in 1561 patients $(72.7 \%)$. The percentage of patients shown to have an aneurysm by this method for each year as illustrated in Fig. 1 was fairly stable over the past 13-14 years. Neither aneurysm nor AVM were demonstrated in 585 patients, $385(65.8 \%)$ of whom proceeded to vertebral angiography (VA) the results being shown in Table 2. Yearly incidences of AVM detection by BCA, and either aneurysm or AVM detection by VA are not given as the annual numbers are too small to provide any reliable indication of possibly changing incidence over the years.
TABLE 2. Results of vertebral angiography in spontaneous subarachnoid haemorrhage when bilateral carotid angiography was negative (1959-80 inclusive)

\begin{tabular}{ccc}
\hline $\begin{array}{c}\text { Total number } \\
\text { of patients }\end{array}$ & Aneurysm & $\begin{array}{c}\text { Arteriovenous } \\
\text { malformation }\end{array}$ \\
\hline 385 & 48 & 16 \\
$\%$ & 12.5 & 4.2 \\
\hline
\end{tabular}

\section{Discussion}

It will be seen that in this series $72.7 \%$ of patients sustaining spontaneous SAH had either aneurysm or AVM or both on BCA, and that of 585 remaining patients, 385 proceeded to VA. The reasons why not all 585 patients went on to VA are many. Some patients had other lesions on BCA such as evidence of intracerebral haematoma suggesting primary intracerebral haemorrhage with extension into the subarachnoid space. Others were considered too ill or elderly to justify the increased risk of VA, especially when taking into account the practical difficulties of surgical treatment of any aneurysm that might be demonstrated on the hind brain circulation. Some patients declined to consent to VA and others died before the investigation could be performed. However, an important factor in the decision as to whether VA should be performed after negative BCA is the incidence of demonstration of previously undetected aneurysm which in this series is $12.5 \%$, an additional $4.2 \%$ having an AVM. Vertebral angiography may also be considered necessary even when one or more aneurysms have already been shown on BCA, as the presence of additional aneurysms on the hind brain circulation may affect management.

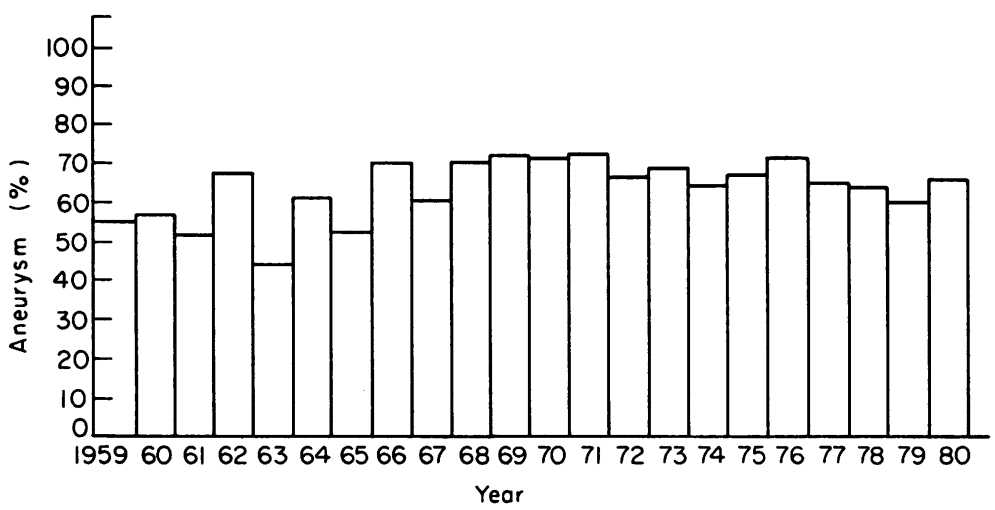

FIG. 1. Incidence of aneurysm demonstration by bilateral carotid angiography in spontaneous subarachnoid haemorrhage (1959-80 inclusive). 
TABLE 3.

\begin{tabular}{|c|c|c|c|c|c|c|}
\hline Author & Year & Data & $\begin{array}{c}\text { Number } \\
\text { of } \\
\text { patients }\end{array}$ & $\underset{\%}{\text { Aneurysm }}$ & $\begin{array}{c}\text { Aneurysm } \\
+ \\
\text { AVM } \\
\%\end{array}$ & $\begin{array}{c}\text { AVM } \\
\text { alone } \\
\%\end{array}$ \\
\hline McKissock, Paine and Walsh & 1958 & $\begin{array}{l}\text { Angiography, operation, } \\
\text { post-mortem }\end{array}$ & 455 & 57 & $0 \cdot 2$ & 6 \\
\hline Levy & 1960 & Carotid angiography & 164 & 39 & - & 14 \\
\hline Locksley, Sahs and Sandler & 1966 & Angiography, post-mortem & 5436 & $54 \cdot 3$ & $0 \cdot 7$ & $6 \cdot 5$ \\
\hline Richardson & 1969 & Angiography, post-mortem* & 3042 & 52 & - & 5 \\
\hline Rogers, Garner and Jacques & 1977 & Angiography & 138 & 63 & - & 0.7 \\
\hline Forster et al. & 1978 & Pan-angiography & 529 & 64 & - & 8 \\
\hline Present series & 1982 & BCA & 2146 & $65 \cdot 2$ & 0.6 & $6 \cdot 9$ \\
\hline Spatz and Bull & 1957 & VA after negative $\mathbf{B C A}$ & 60 & 13 & - & 13 \\
\hline Present series & 1982 & VA after negative BCA & 385 & $12 \cdot 5$ & - & $4 \cdot 2$ \\
\hline
\end{tabular}

*Figures based on analysis of cases admitted to Atkinson Morley's Hospital with the diagnosis of SAH and therefore may contain information obtained from operation and post-mortem in addition to angiography.

The incidence of these abnormalities in spontaneous SAH will depend upon the method of study and the selection of patients. The main angiographic series are shown in Table 3, along with the present series for comparison. Several reports do not specify the type of angiography performed, and although the majority of patients will have had carotid angiography it is not always possible to be sure that this has been bilateral, and some information from VA may also have been included. The series of Rogers, Garner and Jacques (1977) is based on both BCA and VA in every patient, with repeat studies in those patients in whom only 'spasm' was shown on initial investigation. In addition, some series contain information obtained at operation or post-mortem.

The annual incidence of aneurysm demonstration by BCA has remained fairly stable over the past 13 or 14 years. It is appreciated that many factors are involved, and that changing incidence does not merely reflect changes in anaesthetic and radiological technique. Improvement in both these techniques should make angiography safer and, therefore, perhaps more elderly patients are now subjected to this investigation than before, with a higher incidence of arteriosclerotic rather than aneurysmal haemorrhage (Walsh, 1956). Timing of angiography in relation to the initial haemorrhage may also affect the incidence of aneurysm demonstration, the presence of vascular 'spasm' in the early stages and the selective effect of mortality in the later stages both tending to reduce this incidence.

\section{References}

DANDY, W.E. (1944) Intracranial Arterial Aneurysms, p. 147. Comstock Publishing Co., Ithaca, New York.

Forster, D.M.C., Steiner, L., Hakanson, S. \& Bergval, U. (1978) The value of repeat pan-angiography in cases of unexplained subarachnoid hemorrhage. Journal of Neuro:surgery, 48, 712.

HASSLER, O. (1961) Morphological studies on the large cerebral arteries, with reference to the aetiology of subarachnoid haemorrhage. Acta psychiatrica scandinavica, 36 (Suppl. 154), 1.

HAYWARD, R.D. (1977) Subarachnoid haemorrhage of $\stackrel{\mathbb{D}}{2}$ unknown aetiology. A clinical and radiological study of $\overrightarrow{\bar{D}}$ 51 cases. Journal of Neurology, Neurosurgery and Psy- 윽 chiatry, 40, 926.

Hook, O. (1958) Subarachnoid haemorrhage. Prognosis when angiography reveals no aneurysm. A report of $138 \%$ cases. Acta medica scandinavica, 162, 493.

LEVY, L.F. (1960) Subarachnoid hemorrhage without arteriographic vascular abnormality. Journal of Neurosurgery, 17, 252.

Locksley, H.B., SAHS, A.L. \& SANdler, R. (1966) Report on the cooperative study of intracranial aneurysms and 0 subarachnoid hemorrhage. Section III. Subarachnoid 3 hemorrhage unrelated to intracranial aneurysm and $\mathrm{A}-\mathrm{V}$ malformation. Journal of Neurosurgery, 24, 1034.

McKissock, W., Paine, K. \& Walsh, L. (1958) Further $D$ observations on subarachnoid haemorrhage. Journal of 음 Neurology, Neurosurgery and Psychiatry, 21, 239.

RichARDSON, A. (1969) Subarachnoid haemorrhage. British $\mathrm{N}$ Medical Journal, 4, 89.

Rogers, D.T., GARner, J.T. \& JaCQues, S. (1977) Sub- ㅇ arachnoid hemorrhage. Diseases of the Nervous System, N 38, 825.

SPATZ, E.L. \& BULL, J.W.D. (1957) Vertebral arteriography in the study of subarachnoid hemorrhage. Journal of Neurosurgery, 14, 543.

WALsH, L.S. (1956) Subarachnoid haemorrhage. Acta radiologica, 46, 321 . 